\title{
Principle and Design of Cooling System on multi-function Wet Type Multi-disk Brakes
}

\author{
Chuanwei Zhang, Wang Miao \\ Xi'an University of Science and Technology, China \\ *1565106086@qq.com
}

Keywords: multi-function Wet Type Multi-disk Brake; design; forcing cooling; Self-cooling

\begin{abstract}
This paper presented types of wet brake, structure and principle of multi-function wet type multi-disk brake, focusing on its principle of cooling system and design of fully-closed multi-function multi-disk wet brake, as well as calculated and analyzed the cooling system of the vehicle brake on different kinds of cars.
\end{abstract}

\section{Introduction}

Drumbrake was for the first time applied in mechanical engineering, which adopted the sealing brake pads on the structure, so in the case of the repeated braking, the generated wear debris cannot be dissipated, resulting a great impact on the smooth degree of the brakes in the braking process. Afterwards, the disc brakes with superior braking performance appeared, but the caliper disc brakes had high friction surface pressure per unit area. Therefore, it required a higher anti-pressure ability for the friction disc material in the condition of high temperature. This for friction disc material in the case of large temperature compressive ability put forward higher requirements. At present, the more advanced brakes at home and abroad is wet brake, which is widely used in the mining machinery and engineering machinery. Wet brake is a kind of multi-disc brake, which friction element is enclosed within the brake shell. This brake has a stable braking performance and strong anti-pollution ability on the basis of the good performance of the previous at the front of the two types of brake. But this kind of brake must be equipped with a set of cooling system. If it is poorly designed the cooling system was designed improperly, the friction heat of the brake cannot be distributed in the continuous braking process, causing the temperature of the brake chamber rises and oil deterioration, braking performance degradation even cannot work[1-2]. Therefore, in order to ensure brake works safely and, its brake cooling system must be designed appropriately.

\section{The Structure And Principle Of Multi-function Wet Type Multi-disk Brakes}

According to the functions and working principle, wet brake is divided into some types, including Ordinary Wet Type Multi-disc Brake, Wet Multiple Disk Pressure Loss Brake, Multi-function Wet type Multi-disk Brake[3].The widely used wet brake in the mining machinery and engineering machinery is Multi-function Wet type Multi-disk Brake. The structure is shown in Fig.1.

More than half of the brake friction plates area are immersed in the lubricating oil. Many grooves exist on the friction plates. Most of the heat in the brake friction plates generated by the friction will be dissipated through the lubricating oil and housing, avoiding the internal temperature rise too high and damage the brake component part.

The brake integrated the function of Ordinary Wet Type Multi-disc Brake and Wet Multiple Disk Pressure Loss Brake, which realized the tri-function of driving brake, parking brake and emergency brake and do not need the second brake system.

The internal splines and the spline shaft of the movable friction plates inner ring was connected through the spine, which can rotate along with the movable friction plates. The connection of the external splines of the static friction plates and brake shell was by splines. Movable friction plates and static friction plates are 
alternate arrangement and the driving brake and parking brake are respectively controlled by two different hydraulic oil. Driving braking force is produced by the hydraulic oil press on the driving brake piston surface. When the pressure oil comes into driving brake piston of oil chamber, the driving brake piston pushes static friction plates to press movable friction plates generating friction, then the wheels are braked. When the pressure of oil is relieved, return spring makes the driving brake piston depart from the static friction plates so that movable friction plates depart from the static friction plates, releasing the braking force.

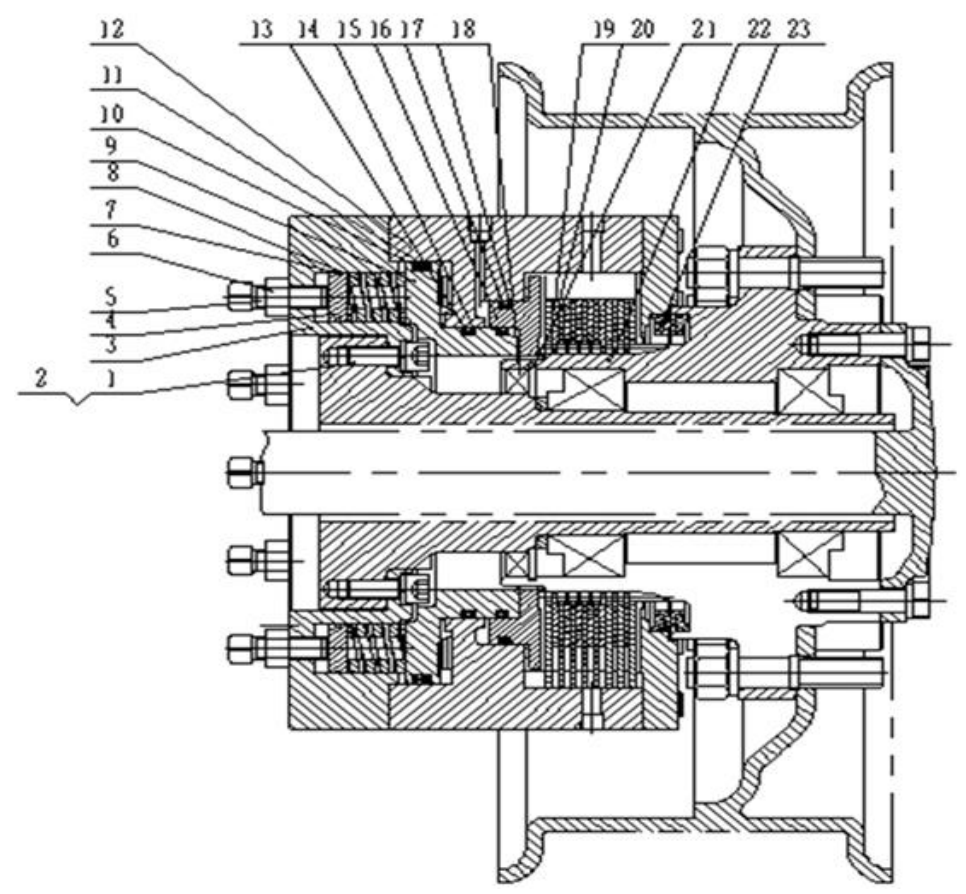

Fig. 1.Structure of Multi-functionWet Type Multi-diskBrakes

1- screw; 2 - spring washer; 3 - connection housing; 4- spring plate; 5- squareflatand tight set screw 6- nut; 7-O-rings;8- rectangular cross-section spring; 9- parking brake piston; 10- collar; 11- star-ring; 12- the middle cylinder; 13- collar;14- star-ring; 15- driving brake piston; 16- collar; 17- star-ring; 18- skeleton Seal; 19- movable friction plate;20- static friction plate; 21- spring collar; 22- spline shaft; 23- floating oilseal.

The parking brake force was generated by the rectangular cross-section spring. During driving, when the pressure oil in the oil chamber of the parking brake piston reached rated pressure, pressure oil pressed on the surface of the parking brake piston to make it out of the driving brake piston and compress the springs with rectangular section and movable friction plates depart from the static friction plates, following a non-parking brake status. When the parking brake or engine broke down or the tubing burst, the rectangular cross-section springs push the parking brake piston, thus the driving brake piston pushes static friction plates generating friction then wheels are braked, and ensured the security.

\section{The Wet Brake Cooling Analysis}

The totally enclosed multi-disc wet brake is mainly used the circulation of the fluid for cooling, which can be divided into forced cooling and self-cooling. For the forced cooling, the cooling oil is introduced into the brakes from the outside circulation, flows through the friction disk then flows out, taking away brake heat. Self-cooling is relied on the cooling oil in the brake and brake of the shell for cooling. Due to the different cooling, brake and bridge structures are different. It have a hub seal before the support bearing in forced cooling, while no in self-cooling. The structure of the forced cooling is complex, but it has a strong cooling ability. The structure of self-cooling is simple, while its cooling capacity is relatively weak. The cooling system is designed through the accurate calculation of the generated heat by the brake during braking and the removed heat by cooling oil, and radiated heat into the atmosphere by the brake surfaces. The flow rate of the cooling pump was determined by the balance of them[4]. 


\section{Calculation And Design Of The Cooling System}

The consumed work of the friction moment between the fixed disc brake and friction plates is equal to the energy ( $E$ ) consumed by the truck's braking, and the truck's braking energy $E$ is equal to the sum of the kinetic energy $E_{1}$ and potential energy $E_{2}$ of the vehicle, namely,

$$
E=E_{1}+E_{2}=\frac{m v^{2}}{2}+\frac{m g h}{2}
$$

In the equation:

$E$ - The total heat generated when the vehicle braking, $J$;

$E_{1}$ - The kinetic energy generated during braking, $J$;

$E_{2}$ - Potential energy generated when the vehicle braking, $J$;

$v$-Initial speed of the vehicle before braking, $\mathrm{m} / \mathrm{s}$;

$g$-Acceleration of gravity, $\mathrm{m} / \mathrm{s}^{2}$;

$h$-The road slope height, $m$;

$m$-The average mass of the vehicle, $m=\left(m_{1}+m_{2}\right) / 2, k g$;

$m_{l}$ - Mass of the empty vehicle, $\mathrm{kg}$;

$m_{2}$ - Mass of the vehicle loaded with goods, $\mathrm{kg}$.

As the potential energy of the vehicle at top reaches the maximum, and is zero at the bottom of the hill, the potentialenergy takes the mean value while calculation, which is half of the value at top, when the slope is not too sharp,

$h \approx L K$

$L$ - the slope length, $m$;

$K$-slope, \% .

If the total running cycle of the vehicle is $T$.In this cycle, the number of braking is $n_{1}$ at high speed $v_{1}$, and $n_{2}$ at low speed $v_{2}$, then

$$
E_{1}=\frac{n_{1} m v_{1}^{2}}{2}+\frac{n_{2} m v_{2}^{2}}{2}
$$

The total heat produced per minute for each brake

$h \approx L K$

Assuming the ambient temperature around is $t_{0}$. The temperature of the oil flowing into the brake is $t_{1}$ and the allowed temperature of the oil flowing out of brake is $t_{2}$. So a portion of the heat generated by the brake supply the oil temperature rising from $\mathrm{t}_{1}$ to $\mathrm{t}_{2}$, and the other dissipates into the atmosphere through the surface of the brake. Therefore,

$Q_{2}=\left(t_{2}-t_{1}\right) C \rho Q+\mu\left(t_{2}-t_{1}\right) A$

In the equation,

$Q_{1}$ - The cooling ability of a brake, $J / \min$;

$\mathrm{C}$-The specific heat capacity of the oil, usually take $C=(16.74-20.93) \times 10^{2} \mathrm{~J} /\left(\mathrm{kg} \bullet{ }^{\circ} \mathrm{C}\right)$;

$\rho$ - The density of oil, $\rho=900 \mathrm{~kg} / \mathrm{m}^{3}$;

$\mu$-The heat transfer coefficient of the brake, $J /\left(m^{2} \times \min \times{ }^{\circ} \mathrm{C}\right)$;

$A$ - The cooling area of the brake, $\mathrm{m}^{2}$; 
$Q$-The flow rate of the cooling oil through a brake, $\mathrm{m}^{3} / \mathrm{min}$.

According to heat balance, $Q_{1}=Q_{2}$, the oil flow of each brake is obtained as follows:

$Q=\frac{E-4 \mu T\left(t_{2}-t_{0}\right) A}{4 T\left(t_{2}-t_{0}\right) C \rho}$

If $E-4 \mu T\left(t_{2}-t_{0}\right) \quad A \leq 0$, the brake can adopt self-cooling, conversely forced cooling must be adopted in the brake.

\section{Forced Cooling Loop}

Wet brakes are fully enclosed, which will generate a lot of heat in the brake. If there is no proper cooling system, the brake temperature quickly exceeds the rated temperature of the brake. At this time, the performance of the brake will drop, even be damaged. The selection of the cooling mode is based primarily on the balance of the braking strength and heat capacity. The cooling loop shown in Fig. 2 can be an independent circuit, or connected to the other loop, such as steering circuit, but the pressure of the loop must be not more than $0.069 \mathrm{MPa}$. The pump flow can be calculated by the method. Here it is no longer accounted one by one in detail.

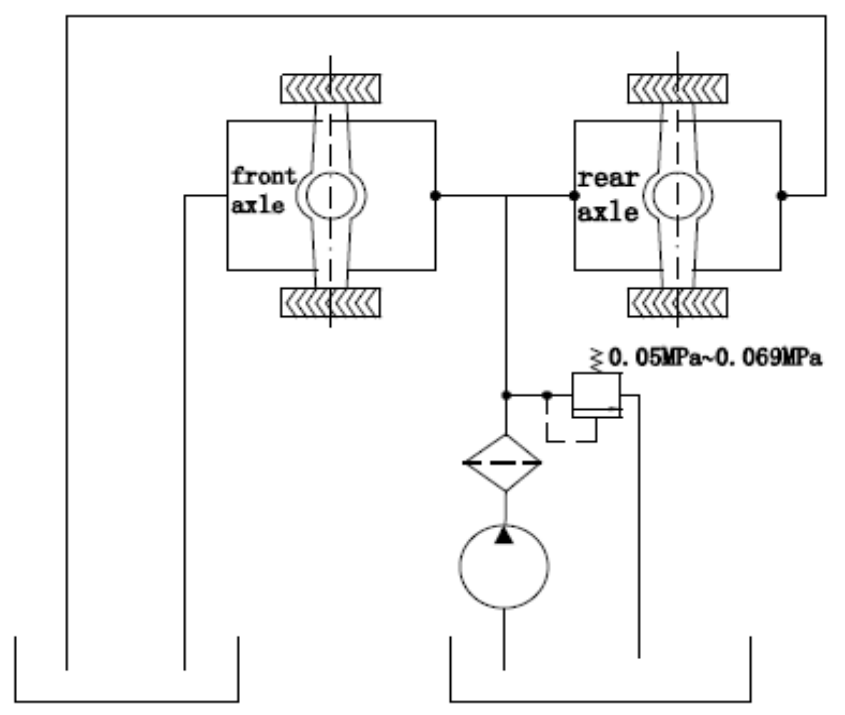

Fig. 2.Cooling oil loop

Example 1. According to the conclusions above, taking a mining car as an example, the car ran for $500 \mathrm{~m}$ at the speed of $10 \mathrm{~km} / \mathrm{h}$ on the ramp with slop angle of $12^{\circ}$, in which $m_{1}=3600 \mathrm{~kg}, m_{2}=5600 \mathrm{~kg}, \mathrm{v}=2.8 \mathrm{~m} / \mathrm{s}$, $T=3 \min , t_{0}=27^{\circ} \mathrm{C}, t_{1}=50^{\circ} \mathrm{C}, t_{2}=80^{\circ} \mathrm{C}, \mu=465 \mathrm{~J} / \mathrm{m}^{2} \mathrm{~s}^{\circ} \mathrm{C}, A=0.4 \mathrm{~m}^{2}$. Following the parameters provided above,

$$
\begin{aligned}
& m=\frac{m_{1}+m_{2}}{2}=4600 \mathrm{~kg} \\
& E=E_{1}+E_{2}=\frac{m v^{2}}{2}+\frac{m g h}{2}=1370432 \mathrm{~J} \\
& 4 \mu T\left(t_{2}-t_{0}\right) \quad A=4118040 \mathrm{~J}
\end{aligned}
$$

So, $E-4 \mu T\left(t_{2}-t_{0}\right) \quad A=-2747608 J \leq 0$

According to the parameters provided above shows that $E-4 \mu T\left(t_{2}-t_{0}\right) A \leq 0$, the brake can adopt the way of self-cooled cooling. So the brake cooling system of the light vehicle widely used in the mine at present meet the design requirements. 
xample 2. As known the main parameters of the underground loader type:

$$
\begin{aligned}
& m_{1}=3500 \mathrm{~kg}, m_{2}=5100 \mathrm{~kg} ; v_{2}=1.6 \mathrm{~m} / \mathrm{s}, n_{1}=2, v_{1}=6.6 \mathrm{~m} / \mathrm{s}, \mathrm{n}_{2}=2 ; L=40 \mathrm{~m}, \mathrm{~K}=12 \% ; \mathrm{T}=1.5 \mathrm{~min}, \\
t_{0}= & 27^{\circ} \mathrm{C}, t_{1}=80^{\circ} \mathrm{C}, t_{2}=90^{\circ} \mathrm{C}, \\
m & =\frac{m_{1}+m_{2}}{2}=4300 \mathrm{~kg} \\
h & \approx L K=4.8 \mathrm{~m} \\
E_{1} & =35260 \mathrm{~J} \\
E & =E_{1}+E_{2}=18523 \mathrm{~J}
\end{aligned}
$$

The cooling area of the brake is taken $A=0.2 \mathrm{~m}^{2}$, the shell material is $Q T 450-10$, and the coefficient of heat transfer is $\mu=1380 \mathrm{~J} /\left(\mathrm{m}^{2} \cdot \mathrm{min} \cdot{ }^{\circ} \mathrm{C}\right)$

Therefore, the total cooling capacity for the four brakes is

$$
4 \mu T\left(t_{2}-t_{0}\right) \quad A=104328 \mathrm{~J}
$$

Due to $E-4 \mu T\left(t_{2}-t_{0}\right) A=34195 \mathrm{~J}$

The underground loader LW166 must use forced cooling.

$$
Q=\frac{E-4 \mu T\left(t_{2}-t_{0}\right) A}{4 T\left(t_{2}-t_{0}\right) C \rho}=0.0036 \mathrm{~m}^{3} / \mathrm{min}=3.5 \mathrm{~L} / \mathrm{min}
$$

Because the pump speed is $2400 \mathrm{r} / \mathrm{min}$, the displacement of the pump is $Q=5.83 \mathrm{~cm}^{3} / \mathrm{r}$. The chosen pump with a displacement not less than $5.83 \mathrm{~cm}^{3} / r$ can meet the requirements [5].

\section{Conclusions}

From the calculation and analysis above, we can judge when a self-cooling or forced cooling should be chosen in the different occasion in order to avoid the high manufacturing costs, which is brought by the forced cooling. If the reality was better than the assumptions, it proved that the flow rate of the hydraulic pump could meet the cooling requirements. On the contrary, the thermal balance should be recalculated and hydraulic pump should be re-elected to avoid the degradation of the braking performance or damage to brakes.

\section{References}

[1] Jianhua Yu, Principle and Design of Cooling System on Wet Type Multi-disk Brakes for Coal Mine [J]. Coal Mine Machinery, 2011, 11:25-26.

[2] ZAGRODZKI Przemyslaw, TRUNCONE Samuel A. Generation of Hot Spots in a Wet Multi-disk Clutch During Short Term Engagement [J].Wear, 2003, 254:( 5 /6) $474-491$.

[3] Chan D. Further developments of the wet braking system [C].International Conference -Braking,2004: 225-239 .

[4] Mengxiong Gao. Design of closed multiple disc wet brakes cooling system [J]. Mechanical Engineering, 1999, 02:21-22+49.

[5] Daxian Cheng. Mechanical design manual [M]. Beijing: chemical industry press, 2002. 